\title{
Sexualidad, agresión y autonomía en la mujer. Contribuciones psicoanalíticas actuales
}

\author{
Roxana Hidalgo Xirinachs
}

\begin{abstract}
Resumen
Este texto consiste en una discusión sobre las relaciones entre los aportes modernos de la teoría psicoanalítica a la comprensión de los procesos de socialización de las mujeres y los aportes de las teorías de género y el feminismo producto de los movimientos de liberación de las mujeres que se han desarrollado durante el último siglo. Primero se abordan brevemente los cambios más importantes que se han desarrollado en las relaciones entre los géneros durante las últimas décadas. Posteriormente se realiza un acercamiento a la comprensión de las relaciones entre los géneros en la teoría psicoanalítica desde una perspectiva crítico-social. Para finalmente abordar las relaciones entre las manifestaciones de la sexualidad, la agresión y la autonomía en la mujer, especialmente en relación con los procesos de separación y reconocimiento en el desarrollo de la mujer como sujeto.
\end{abstract}

\begin{abstract}
This text consists on a discussion among the relations between the modern contributions of the psycoanalitic theory to the understanding of the socialization processes of women and the contributions of gender theories and feminism, product of the women's liberation movements that have been developed during the last century. The most important changes that have been developed in the relations between the genders during the last decades are briefly approached first. An approach to the understanding of the relations between the genders in psycoanalitic theory from a social-critique perspective is done later. To finally approach the relations between the woman's sexuality manifestations, aggression and autonomy, specially in relation with the separation and recognition processes on the woman's development as a subject.
\end{abstract}




\section{Transformación en las relaciones entre los géneros a comienzos del Siglo XXI}

Explorar la sexualidad pero sobre todo la agresión femenina implica hasta hoy día enfrentarse con el desconcierto y la angustia que la relación con lo extranjero, experimentado como un otro irreconocible, provoca en el sí mismo. No sólo lo femenino, sino en particular las diversas manifestaciones de la sexualidad y la agresión en la mujer han sido mediante múltiples fantasías inconscientes, "tabuizadas" a lo largo de la historia de Occidente. La mujer que se apropia de sus propios deseos sexuales y que actúa de acuerdo con sus propios intereses, que rompe con la tradición y subvierte el lugar social asignado a la mujer es representada a menudo en la literatura o la mitología a través de figuras deformes o grotescas. En la imagen de la esfinge devoradora, de la medusa que petrifica o de la bruja que seduce con sus brebajes mágicos aparece la agresión femenina reducida a la fantasía inconsciente de la mujer como personificación de un poder destructivo inexorable. Desde una perspectiva patriarcal la tendencia en la mujer hacia la autonomía tiende frecuentemente a estar asociada con la desmesura, la aberración o la crueldad como expresiones de aquello que trasciende la cultura y se ubica en el mundo de la naturaleza. La imagen de lo femenino como continente oscuro, como aquello siniestro que se vuelve inabordable para la conciencia ha sido un tema de análisis fundamental dentro de la teoría psicoanalítica desde sus orígenes. El abordar esta premisa desde una perspectiva crítica recuperando los aportes de los estudios modernos sobre la feminidad y las relaciones entre los géneros dentro de la teoría psicoanalítica constituye un principio fundamental para acercarse a la comprensión de la feminidad y la masculinidad en la actualidad. Al mismo tiempo esta perpectiva crítica debe ir acompañada de una interpretación etnológica, sociológica e histórica que posibilite una comprensión social crítica de las transformaciones en las relaciones entre los géneros que se vienen desarrollando en el último siglo.

La realidad de la mujer y, más recientemente, de las relaciones entre los géneros ocupa hasta hace solo algunas décadas un lugar significativo en el discurso científico. Un lugar que se ha venido construyendo como producto de las lentas, aunque profundas, transformaciones que se han venido produciendo en las relaciones entre las mujeres y los hombres desde finales del siglo pasado. Las mujeres habían ocupado hasta principios del Siglo XX una especie de lugar vacío en la historia oficial de la humanidad. Mayoritariamente ausentes de la escritura y de las estructuras del poder político y económico dominantes, su historia constituía un espacio nebuloso cubierto por la extraordinaria fantasía de aquellos grandes escritores, artistas, médicos, filósofos, y científicos que hasta hace poco habían plasmado de forma escrita la historia de Occidente.

A partir de este escenario de cambios acelerados voy a tratar de acercarme a la controversial situación que caracteriza las relaciones entre los géneros y las imágenes sobre la feminidad en la realidad actual. El Siglo XX marcó, en este sentido, un hito histórico en el que la transformación de los roles de género se viene enfrentando con una realidad completamente nueva. Por primera vez en la historia de Occidente, las mujeres van a ocupar un lugar común con los hombres en relación con los derechos sociales, legales y políticos. Desde la igualdad de derechos en relación con el voto, el estudio y el trabajo, hasta la desaparición lenta pero gradual del legendario tabú de la mujer como objeto de intercambio, constituyen condiciones extraordinarias que hace apenas un siglo eran todavía inimaginables o simples fantasías utópicas de algunas disidentes. Para poder compartir las nuevas potencialidades de la modernidad, que la ilustración, la secularización y la individualización desencadenaron y que hicieron posible el surgimiento del sujeto burgués, las mujeres tuvieron que esperar el lento avance de la historia. Sin embargo, los profundos cambios que esta igualdad de derechos ha provocado en el último siglo están lejos de consolidarse en la realidad psíquica y social de las relaciones entre los géneros.

Estas nuevas potencialidades de la modernidad no han estado libres de contradicciones que hasta hoy en día siguen considerándose insuperables. En relación con el desencantamiento y la descentralización del mundo moderno, afirma Bauman (1995): "Para la modernidad, la guerra contra la mística y la magia se convirtieron en una guerra de liberación que produjo una declaración de independencia de la razón. Ésta fue una declaración de guerra, que hizo del mundo natural, no trabajado, un enemigo. Como en todos los genocidios, el mundo de la naturaleza (a diferencia de la casa de la cultura que la modernidad se dispuso a construir) tuvo que ser decapitado, para robarle, a 
ésta, la voluntad autónoma y la fuerza de resistencia" (p. 9) ${ }^{1}$. La racionalidad instrumental que ha caracterizado este desencantamiento del mundo ha transformado la autorreflexión y la capacidad individual de actuar y decidir del sujeto moderno en una coraza inviolable, cuya función parece ser la de protegerlo contra su propia subjetividad. La inseguridad, el desorden y la multiplicidad que caracterizan la vida misma pasaron a convertirse en los monstruos de la modernidad.

Los viejos esquemas patriarcales que estructuraban las relaciones entre los géneros alcanzaron con la modernidad extremos difíciles de superar. La mujer pasó a convertirse en la personificación ideal de las fuerzas impulsivas y caóticas de la naturaleza salvaje, encarnada además por aquellos otros que provenían de las clases sociales sometidas, de países extranjeros y sobretodo de las culturas no europeas recién conquistadas. La feminidad quedó asociada de forma aparentemente indisoluble con la oscuridad, el caos, la carencia, la negatividad o la irracionalidad que de forma extrema han caracterizado la otredad en la cultura occidental desde el surgimiento del mundo moderno. Las relaciones de poder estructurales que han marcado la desigualdad social hasta el presente siguen estando acompañadas de una relación jerárquica entre los géneros, en la que los hombres gozan frente a las mujeres de una posición preferencial tanto en el espacio público como privado. En relación con esta desigualdad que sigue siendo difícil de superar, a pesar de las trasformaciones en las relaciones entre los géneros antes apuntadas, afirma Musfeld (1997):

\begin{abstract}
"Esta jerarquía selló la valoración de los géneros en todos los campos de la vida social y cultural: comenzando con la remuneración inferior, la exclusión de las mujeres de las funciones directivas y del acceso a las posiciones de poder, hasta la representación carencial de los intereses femeninos en el lenguaje, la cultura y los medios de comunicación, así como, en los comportamientos discriminatorios contra la mujer en todos los niveles de comunicación tanto verbales como no verbales. Esta dominación encuentra su manifestación más dramática en la violencia contra las mujeres” (p. 13).
\end{abstract}

La antigua separación entre el orden y el caos, entre la razón y la naturaleza o, si se quiere, entre lo masculino y lo femenino, surge en el mundo moderno como tensión entre la iluminación del conocimiento cientifíco-tecnológico y la oscuridad de la naturaleza o las tradiciones culturales. Actualmente, esta lejana escisión se manifiesta en el conflicto entre el futuro esclarecedor de la modernidad -personificado en la razón instrumental y el desarrollo acelerado de la tecnología- y el pasado tenebroso de las pasiones del cuerpo o los deseos del inconsciente. El viejo enfrentamiento entre civilización y barbarie, o si se quiere, entre ilustración y mitología, nos sigue acompañando. Sin embargo, como Adorno y Horkheimer en la "Dialéctica de la Ilustración" ya habían afirmado: "el mito es ya ilustración; la ilustración recae en mitología" (1947, p. 56). La polarización deja de ser tal, para aparecer en su tensión dialéctica, en la relación indisoluble de polos encontrados. Esta posición significó un avance en relación con la concepción del mundo estructurada a partir de la escisión en categorías opuestas y excluyentes entre sí, característica de la cultura occidental. Sin embargo, al mismo tiempo, la propuesta de los autores aparece como un camino sin esperanza, sin salida, en una época en que el futuro, después de la segunda guerra mundial, se presentaba difícil. Como consecuencia de esta desesperanza, se declaró la identificación entre ilustración y dominio.

Hoy día, después del trastocamiento en la relación entre los géneros que se ha producido en las últimas décadas, parece de nuevo importante volver la mirada hacia aquel legendario enfrentamiento entre la mitología y la ilustración. Surge, como una nueva urgencia, la búsqueda de una tercera opción, de un camino más allá de la separación dicotómica del mundo, y más allá de la identidad individual escindida, que desemboca en una negación de la diferencia entre los géneros. Aparece la posibilidad, de que la lucha entre la vida y la muerte, entre los dioses del Olimpo y las fuerzas ctónicas expulsadas en el Hades, o, finalmente, entre la dureza masculina de las leyes culturales y la fluidez femenina de las pasiones corporales, no implique el necesario dominio de un polo sobre el otro. Lo posible aparece como un trastocar los viejos lugares de la devaluación o exclusión del otro, de aquello vivido como extranjero para el sí mismo o experimentado como no idéntico. Las aparentemente indisolubles fronteras que han acompañado la diferencia entre los géneros desde hace siglos se han resquebrajado en una medida que hasta hace poco hubiera sido inimaginable. Han quedado espacios libres sin fronteras sólidas en los que los hombres y las mujeres disuelven mutuamente las imágenes estereotipadas prestablecidas en los roles de género. Los viejos roles, gestos y máscaras dejan de funcionar en su absolutización, en su separación

1 Traducciones como éstas en el texto constituyen versiones libres de la autora. 
irreconciliable. Lo novedoso de las experiencias de vida y la incertidumbre en las relaciones entre los géneros producen espacios potenciales nuevos. Tanto la angustia, la desconfianza y la decepción frente a lo desconocido, como el reconocimiento de la diferencia entre los géneros y la ambivalencia frente a los roles tradicionales, abren la posibilidad de un nuevo encuentro entre los hombres y las mujeres.

Sin embargo, a pesar de estos espacios potenciales, no sólo en los vínculos reales entre los hombres y las mujeres, sino también en las representaciones simbólicas de la cultura seguimos encontrando una dominación de lo masculino sobre lo femenino. Esta relación jerárquica es atravezada por fantasías y mitos inconscientes de carácter patriarcal. Como propone RohdeDachser (1991), no sólo en la literatura, el arte y la mitología, sino también en la teoría psicoanalítica domina una tendencia a la creación de fantasías masculinas, que están al servicio de la producción social del inconsciente: "Imágenes sobre lo femenino en la literatura y el arte y aquellas semejantes en la teoría psicoanalítica provienen de las mismas fantasías inconscientes colectivas y pueden, por lo tanto, en cierto grado ser consultadas para una interpretación recíproca -no para ser mutuamente legitimadas, sino para, de esta forma, ser esclarecidas" (p. 96). Del mismo modo que en los sueños, encontramos en el arte, la mitología y el psicoanálisis espacios simbólicos, que no sólo están al servicio de la producción de mundos de la vida "tabuisados" socialmente, sino también de la satisfacción de deseos inconscientes colectivos. En otras palabras, estas manifestaciones simbólicas culturales responden a un doble movimiento. Por un lado, tienen una función de resimbolización en relación con la escenificación de mundos de la vida, que subvierten las normas, prohibiciones y tabúes de una época histórica determinada. Por otro lado, tieden a la desimbolización de proyectos de vida conflictivos para el concenso social, que ponen en peligro el orden establecido por un sistema de valores compartido socialmente (ver Lorenzer, 1986). Partiendo de este doble movimiento, a continuación me voy a ocupar de las contradicciones en las imágenes sobre lo femenino dentro de la teoría psicoanalítica, para poder acercarme mejor a la comprensión de la feminidad en la realidad actual.

\section{La comprensión de las relaciones entre los géneros en la teoría psicoanalítica desde una perspectiva crítico-social}

La comprensión del desarrollo psicosexual y la formación de la identidad en la mujer dentro del psicoanálisis ha estado teñida, desde Freud, por la imagen de oscuridad e inaccesibilidad que ya históricamente pertenecía a lo femenino desde los griegos. El contraste entre, por un lado, la posición crítica de Freud con respecto a la sexualidad adulta e infantil (Freud, 1905 b, 1915 y 1916/17) y, por otro lado, su concepción de la sexualidad femenina (Freud, 1905 a, 1925, 1931 y 1933), ha sido a partir de los años setenta ampliamente discutido dentro y fuera de la teoría psicoanalítica. Una multiplicidad de autores empezaron, bajo la influencia de los nuevos movimientos feministas, a cuestionarse aquellos temas tabuizados socialmente en torno a la identidad femenina. Con esta segunda fase del movimiento feminista y la correspondiente discusión sobre la feminidad dentro del psicoanálisis, después de una brecha de más de treinta años producto de las experiencias traumáticas ligadas con la segunda guerra mundial, podríamos decir que se inicia una intensa discusión en la que la diferencia entre los géneros pasa a ocupar un lugar central. El desarrollo del Complejo de Edipo en la niña, con las particularidades ligadas a la angustia de castración y la envidia del pene, que hasta ahora habían estado conceptualizadas a partir de la teoría del monismo fálico, van a empezar a ser cuestionadas como consecuencia de los profundos cambios sociales en los roles sexuales, así como, a partir de los nuevos descubrimientos sobre la sexualidad humana (ver Masters y Johnson, 1966; Stoller 1968, 1975). La relación preedípica de la niña con la madre y el papel del padre en el proceso de separación e individuación, la controversia en torno a la excitabilidad vaginal temprana de la niña y el desarrollo particular del Complejo de Edipo en la mujer, influenciado por el rol social de ésta en la sociedad, empiezan a convertirse en puntos controversiales dentro de la teoría psicoanalítica y fuera de ésta. Igualmente, los conflictos particulares de la mujer con respecto a la sexualidad y al manejo de la agresión, asociados con la supuesta tendencia dominante en ésta hacia el masoquismo, la depresión y la culpa, así como, sus mayores dificultades en relación con el proceso de separación-individuación y el desarrollo de una identidad femenina autónoma se han convertido en los ejes centrales de la discusión sobre la diferencia entre los géneros. 
La censura del cuerpo en la mujer, la negación del placer y el erotismo femenino frente a la sexualidad masculina organizada en torno al pene y la erección, y finalmente, la reducción de la diferencia sexual al conflicto entre posesión o carencia, constituyen, dentro de la teoría psicoanalítica, las condiciones básicas para ubicar a la sexualidad femenina en el lugar de lo extranjero. Lo femenino queda de esta forma asociado con aquello desconocido y salvaje, que amenaza con desbordarse si no se le ponen diques culturales adecuados. Asimismo, la agresión femenina aparece como extraña dentro del rol social tradicional de la mujer, vinculado con la maternidad y la capacidad de cuidado y protección de los otros. Ambas experiencias en la mujer quedan reducidas al lugar de la pasividad, la falta de acción y el silencio, o por el contrario, al lugar de la destrucción sin límites, de lo monstruoso e inabordable. Imágenes adecuadas para representarse estas experiencias más allá de la separación en oposiciones binarias no son frecuentes en la teoría psicoanalítica, ni tampoco fuera de sus fronteras.

En este sentido, los trabajos de Cixous y Clément (1975), Irigaray $(1977,1987)$ y Kristeva (1974, 1980) sobre la feminidad están impregnados de fantasías e imágenes utópicas que abren nuevas perspectivas en torno a las particularidades del placer sexual, la creatividad y el lenguaje en la mujer. Estas autoras, influenciadas por el psicoanálisis lacaniano, se proponen una crítica deconstructiva de la estructuración jerárquica del mundo en oposiciones binarias. Oposiciones en las cuales la feminidad y la masculinidad se han enfrentado entre sí como enemigos en una guerra interminable entre los sexos. Esta crítica abarca también al falogocentrismo del pensamiento lacaniano, en el cual el privilegio del falo y la supuesta plenitud orginaria del ser, fundamentalmente masculino, se opone a lo femenino representado como falta. Lo femenino asociado con la fluidez de las pulsiones corporales, es recuperado por las autoras mediante fantasías voluptuosas sobre el erotismo femenino y el cuerpo de la mujer, las potencialidades de una escritura femenina que trasciende los límites endurecidos de la escritura masculina, y la potencialidad creativa de las mujeres asociada con la experiencia particular de la maternidad. Si bien estas autoras terminan cayendo en una nueva imagen bipolar de las relaciones entre los géneros, en la cual las diferencias entre las mujeres de diversas clases sociales, culturas, grupos étnicos o religiosos, queda oscurecida, sus aportes son fundamentales para una comprensión alternativa de la sexualidad y la creatividad femeninas. El énfasis puesto en el concepto de la diferencia entre los géneros las lleva a reconceptualizar las imágenes sobre el placer y la sexualidad en la mujer:

"Su sexualidad (contra Freud) nunca es verdaderamente fálica/genital. A diferencia del placer del hombre, el de la mujer nunca se centra en un órgano o se orienta a una meta: la liberación (de la tensión) orgásmica. Es más bien plural: 'La mujer tiene órganos sexuales más o menos en todas partes. La geografía de su placer está mucho más diversificada, es más múltiple en sus diferencias, más compleja, más sutil que lo que se imagina comúnmente.” (Irigaray, 1985, cit. por Flax, 1990, p. 288).

La sexualidad femenina se reconceptualiza a partir de cualidades propias no derivadas de la negación de lo masculino. La ausencia de pene, la carencia o la falta dejan de ocupar el lugar fundamental de la identidad femenina. Más que la igualdad entre lo femenino y lo masculino, el énfasis está en la diferencia entre los géneros, en la búsqueda de una escritura femenina que nos hable del deseo, el goce y el cuerpo de las mujeres. Si bien esta propuesta rescata la fluídez y la diversidad del placer femenino, oculta aquellas manifestaciones de la agresión en las mujeres, presentes en sus deseos de separación, autonomía, autodeterminación y dominio (Flax, 1990). Nos queda una imagen idealizada del erotismo y la creatividad femeninas, en la que la mujer desprestigiada en el discurso patriarcal es revalorada, pero, al mismo tiempo, queda de nuevo ubicada en el lugar del "otro", de la diferencia.

La interpretación crítica que realizan Schlesier (1981) y Rohde-Dachser $(1990,1991,1996)$ sobre las imágenes de lo femenino en la teoría psicoanalítica, la literatura y la mitología ofrecen una perspectiva nueva sobre la identidad femenina. Una perspectiva en la cual la sexualidad y la agresión en la mujer son desmistificadas para poder ser reconocidas en su diversidad y en su legitimidad. La autoras exploran manifestaciones de la feminidad que trascienden los mitos sobre las imágenes de la madre mala, devoradora y destructiva, la mijer fálica, seductora y asesina, o la mujer castrada, incapaz de autodeterminación y autonomía. Estas imágenes de lo femenino han dominado desde sus orígenes los discursos psicoanalíticos. Proponen como alternativa el acercamiento a una imagen de la mujer como sujeto independiente, con capacidad de autodeterminación y de acción autónoma sobre sus propias vidas. El interés se centra en la búsqueda de una concepción sobre la feminidad que trascienda la imagen devaluada de la mujer como ser pasivo, dependiente, poco agresivo y 
desexualizado. Frente a esta imagen unilateral y unitaria, las autoras exploran imágenes diversas sobre las manifestaciones activas de la sexualidad, la agresión y la autoreflexión en la mujer.

La conceptualización que Kestenberg $(1968,1988)$ y Berstein (1993) realizan sobre la genitalidad femenina considerándola como un sistema abierto determinado por los órganos genitales internos en la mujer constituye otro aporte fundamental. Sus estudios sobre una genitalidad interna en las mujeres, cuya experiencia implica angustias genitales particulares asociadas con los órganos sexuales de la mujer constituyen un avance significativo acerca de la comprensión de la sexualidad femenina y la maternidad. Las fantasías y angustias que surgen de las experiencias sexuales infantiles asociadas con la vagina, el clítoris, el cargar a un hijo en el propio cuerpo, amamantarlo o cuidarlo como hace la madre, entre otros aspectos, ofrecen una comprensión de la sexualidad femenina desde sus propias especificidades. Encontramos en estas autoras imágenes que trascienden las representaciones de la envidia del pene y la angustia de castración como determinantes fundamentales en el desarrollo de la sexualidad en las niñas. Las experiencias sexuales preedípicas producto de la relación temprana con la madre, como imagen dual en la identificación de género, y del proceso de triangulación temprana con la figura paterna, así como las experiencias edípicas que surgen de la identificación con la feminidad y la maternidad, de la rivalidad con la figura materna y del deseo hacia la figura paterna, aparecen como experiencias fundamentales creadoras de identidad en la mujer.

Desde la perspectiva de la teoría de la relaciones objetales, los estudios de Chodorow (1978), Benjamin (1988), Poluda-Korte (1992) y King (1995), en torno al desarrollo psicosexual y la paradoja de la dependencia y la autonomía en la mujer, constituyen aportes fundamentales para comprender la identidad femenina desde los cambios actuales en las relaciones entre los géneros. Estos estudios abarcan una comprensión crítica sobre las complejas relaciones entre feminidad, interdependencia y autonomía en la mujer. Una comprensión que va más allá de la imagen tradicional de la mujer asociada con pasividad, dependencia e inseguridad, en la cual las capacidades de la mujer para la interdependencia, el soporte, la contención y la protección del otro, no necesariamente están disociadas de la acción autónoma, la autodeterminación y la autoreflexión. Los trabajos de Chodorow enfatizan demasiado en la capacidad de la mujer para establecer relaciones con los otros, es decir, para la interdependencia, el vínculo y la solidaridad, frente al distaciamiento, la separación y la autonomía, que serían más bien capacidades de los hombres. Al enfatizar en la separación de estas cualidades, se cae de nuevo en una imagen bipolar de los géneros, en la cual se les asignan lugares rígidos tanto a las mujeres como a los hombres. Las otras autoras sí logran trascender esta imagen unilateral de la feminidad al ocuparse no sólo de las condiciones psicosociales que bloquean o dificultan, sino también de aquellas que facilitan el desarrollo de una identidad autónoma en las mujeres. Al intentar acercarse al proceso de constitución de la mujer como sujeto, estas autoras brindan un aporte valioso al proceso de desmistificación de las imágenes patriarcales sobre la feminidad, dominantes todavía hoy en día en la teoría psicoanalítica. Mientras en estas imágenes la mujer sigue todavía recluida en el mundo enigmático de las pasiones corporales, para estas autoras la mujer, como sujeto con capacidad de autoreflexión y decisión autónoma, regresa al mundo de la cultura.

Los estudios de Dio Bleichmar (1985, 1997), Burín y Meler (1998), Fernández (1992) y Tubert $(1996,1997)$, entre otros, vienen a ofrecer dentro de la compleja realidad de las relaciones entre los géneros en latinoamérica una nueva perspectiva sobre los vínculos entre feminismo, género y psicoanálisis. A partir de la experiencia clínica, de la investigación y de la participación en organizaciones que trabajan con mujeres, estas autoras intentan acercarse a la multiplicidad de experiencias que las mujeres de diversos sectores sociales viven en una época de transformaciones sociales intensas. La especificidad de la realidad latinoamericana como contexto amplio en el que las relaciones entre los géneros adquieren cualidades propias se manifiesta como una inquietud constante entre algunos grupos de psicoanalistas que se han dedicado a estudios sobre la mujer y sobre los géneros en la última década.

Fernández (1992) se ha dedicado a explorar la influencia que el imaginario social, como universo de significaciones predominantes en una sociedad determinada, tiene sobre la construcción de las relaciones entre los géneros. El imaginario social hace que los miembros de una sociedad "enlacen y adecuen sus deseos al poder", es decir, que los controles institucionales se incriban como reguladores en la subjetividad de hombres y mujeres (Mari, 1988, cit. por Fernández, 1992, p. 15). Se podría afirmar que el funcionamiento de los dispositivos de poder se ejecuta en dos niveles que coexisten y se complementan entre sí: 
"Los dispositivos de poder exigen, como condición de su funcionamiento y su reproducción, no sólo sistemas de legitimación, enunciados, normativas y reglas de justificación y sanciones de las conductas no deseables (discursos del orden), sino también prácticas extradiscursivas; necesita soportes mitológicos, emblemas y rituales que hablen a las pasiones y, en consecuencia, disciplinen los cuerpos." (Fernández, 1992, p. 15)

Existen una serie de mecanismos institucionales mediante los cuales los mitos sociales logran su eficacia en el disciplinamiento y en la legitimación del control social. Al respecto, la autora se refiere a la eficacia simbólica, como repetición insistente de las narrativas míticas, y a la violencia simbólica, como voluntad totalizadora y esencialista. Violencia mediante la cual, se instaura un universalismo ahistórico que invisibiliza la diversidad y el proceso sociohistórico de construcción del imaginario social. Algunos de los mitos sociales de la familia burguesa, que surgen con la modernidad, como el mito de la mujer-madre, el de la pasividad erótica femenina y el del amor romántico se concentran en regular, de esta forma, el placer sexual en las mujeres. En este sentido, nos encontramos en la teoría psicoanalítica con un conjunto de objetos prohibidos o denegados, que corresponden a los silenciamientos que se legitiman en estos mitos sociales sobre la feminidad. Estos objetos responden a los lugares psíquicos del cuerpo de las mujeres que no son simétricos con el cuerpo de los hombres. Más allá de la envidia del pene y la angustia de castración, las fantasías y angustias asociadas con las zonas erógenas femeninas como la vulva, los labios menores y mayores, el clítoris, la vagina y los senos, se encuentran invisibilizados en la comprensión psicoanalítica de la sexualidad femenina. Asimismo, frente a una envidia del pene considerada como natural e inamovible, la envidia de la maternidad, en los niños y niñas, apenas se ha empezado a discutir seriamente en los últimos años. Como conclusión, Fernández $(1992,1998)$ propone que se debe superar la negación de la diferencia entre los géneros en el psicoanálisis y, además, se debe construir otra lógica de la diferencia, que supere las concepciones bipolares del mundo. Dentro de la discusión psicoanalítica sobre las relaciones entre los géneros debe abordarse una discusión social crítica en torno a la desnaturalización del patriarcado y la constitución de una lógica de la diferencia que no se base en la exclusión y/o inferiorización de las diferencias.

Dio Bleichmar (1992) realiza una discusión crítica sobre algunos enunciados psicoanalíticos de orientación lacaniana, que a pesar de intentar superar, el peso de lo anatómico en la comprensión freudiana de la feminidad, terminan de nuevo legitimando una imagen bipolar esencialista y ahistórica sobre la mujer. Sin entrar en una discusión profunda de las tesis centrales sobre la feminidad en la teoría psicoanalítca lacaniana, propósito que trasciende en mucho los alcances de este trabajo, voy a comentar brevemente la propuesta de la autora al respecto. Que el orden del lenguaje corresponda con el orden fálico, frente a una mujer que no toda pertenece al orden simbólico, lo que significa que está un poco fuera de la ley, son postulados que legitiman la imagen patriarcal de la mujer como un otro, asociado con la naturaleza desbordante e incontrolable. La mujer tendría acceso a otro goce, un goce femenino, un goce suplementario que escapa al registro fálico y se ubica en un lugar fuera de lo simbólico (p. 141). De igual forma como la mujer bíblica existe gracias al poder divino que la extrajo de la costilla de Adán, la mujer lacaniana existe gracias a la lógica fálica, que corresponde a la ley del padre. Sobre el peso de la cultura en esta imagen de lo femenino, se cuestiona la autora:

"La teoría describe la esencia de la feminidad como esa posición psíquica de 'objeto causa de deseo', redoblando y a la vez silenciando que es ése el papel que la cultura le impone como la 'debida feminidad', y luego cuando lee el fantasma erótico en que la mujer no hace más que obedecer el mandato, desconoce tal imposición y le descubre una falta.”(Dio Bleichmar, 1992, p. 143).

La ley paterna que legisla el deseo humano es sexista, es decir, es producto de un sistema social patriarcal, donde la mujer queda recluida en el lugar de la ausencia o negación de lo masculino. La imagen de la mujer y, no lo humano, como encarnación de la falta, sin explicitar los fundamentos sociales, culturales e históricos que han determinado la desigualdad y la discriminación en las relaciones de poder entre los géneros, pareciera que atrapa a la mujer de nuevo en el limbo de la naturaleza. Al respecto, afirma Dio Bleichmar (1992):

"La masculinidad/feminidad es una normativa, una legalidad presente en el deseo inconsciente y en el Ideal del Yo de todo hombre/mujer, de todo padre/madre de nuestra cultura, que ritualiza y da forma 
a la sexualidad de toda nena/varón, en la dirección desigual que conforma lo que entendemos como diferencias sexuales." (p. 144).

Se podría afirmar, siguiendo a la autora que existe una "falta de una erótica femenina", que reconociendo la diferencia entre los géneros, pueda dar cuenta de las particularidades de la sexualidad femenina.

En relación con la comprensión de la subjetividad desde la dimensión socio-histórica, Meler (1992) se ha dedicado a explorar sobre la influencia que las transformaciones en las relaciones entre los géneros, que se vienen desarrollando en las últimas décadas, tienen sobre la organización familiar. La autora se plantea el desafío de abordar las implicaciones psicosociales de estos cambios en los hogares reorganizados por el divorcio, los hogares monoparentales, los jóvenes que cuentan con independencia habitacional, las personas mayores que viven sólas o en grupos, y los matrimonios homosexuales con o sin hijos, entre otros. Este desafío implica la posibilidad de acercarse a las diversas formas de socialización y de constitución de la subjetividad en la actualidad. En el campo clínico, la autora se cuestiona sobre la necesidad de plantearse un abordaje terapeútico que se enfrente de forma crítica con las consecuencias psicosociales que las relaciones de poder entre los géneros tienen en la constitución de la subjetividad:

"Esta preocupación por evitar una práctica terapéutica sexista es reveladora de un doble compromiso: por una parte, con la transformación de la condición social de las mujeres y, por la otra, con la restitución a la tarea psicoanalítica de su carácter innovador en la búsqueda de la comprensión y el alivio del padecimiento psíquico." (Meler, 1992, p. 185)

Más que la reproducción del imaginario social como fundamento para establecer los criterios de salud mental, la autora propone una apertura hacia las necesidades nuevas y diversas que los pacientes plantean. La práctica terapeútica debe más bien brindar contención y apoyo en el proceso de búsqueda de nuevos modelos identificatorios y patrones de vinculación diferentes.

A partir del análisis sobre las relaciones entre psicoanálisis, feminismo y posmodernismo, Tubert (1995), compara las premisas teóricas y filosóficas que considera son comunes tanto para el psicoanálisis como para el feminismo, modelos de pensamiento que surgieron, ambos, durante la transición del Siglo XIX al Siglo XX:

\begin{abstract}
“Tanto el psicoanálisis como el feminismo, más allá de sus aportaciones al saber acerca del ser humano, se han constituido como modos de cuestionamiento de los conocimientos establecidos, por lo que se sitúan en la dimensión del pensamiento crítico (...) Tanto para el psicoanálisis como para el feminismo, en el eje de sus investigaciones y desarrollos teóricos se localiza la cuestión de la diferencia entre los sexos (...) más allá de sus evidentes diferencias, el psicoanálisis y el feminismo han coincidido en el esfuerzo por comprender la construcción cultural de la diferencia sexual, por localizar las causas de la opresión y de la violencia sexual, y por deconstruir las formas en que nos vemos afectados por nuestra inclusión en el orden simbólico patriarcal (...) Ambos mantienen una relación doble con el pensamiento ilustrado: hijos de la modernidad en el intento de llevar las premisas de la ilustración hasta sus últimas consecuencias, han mostrado, por ello mismo, sus límites y falencias, y han cuestionado sus pretensiones imposibles - la igualdad, la universalidad, la racionalidad $-\mathrm{y}$ sus promesas incumplidas- el progreso y la felicidad.” (p. 7-8, 20)
\end{abstract}

De los tres momentos de producción intelectual que han acompañado a los movimientos feministas -los estudios de la mujer, los estudios de género y los estudios sobre la diferencia entre los géneros, articulado con otros sistemas de diferencias socio-culturales- es fundamentalmente en este tercer momento donde la articulación entre psicoanálisis y feminismo ha tenido su mayor desarrollo. Principalmente, a partir de la década de los años setenta, se ha desarrollado una crítica feminista de los fundamentos teóricos patriarcales en el psicoanálisis. Esta discusión se ha centrado en cuestionar el monismo fálico, que había predominado en la comprensión psicoanalítica sobre la feminidad desde Freud. El análisis de la sexualidad femenina a partir del concepto de diferencia entre los géneros viene a brindar como hemos visto una visión nueva, alternativa, sobre la feminidad. 
De acuerdo con la autora se podría afirmar que tanto el psicoanálisis como el feminismo y el posmodernismo han cuestionado el concepto de sujeto unitario y esencialmente racional que ha dominado desde el surgimiento de la época moderna. Sin embargo, la crítica que realiza el posmodernismo del concepto de sujeto moderno, pareciera que termina negando de forma contradictoria, la existencia del deseo de liberación que diversos sectores sociales manifiestan cotidianamente en sus luchas contra la dominación. Los movimientos de liberación de las mujeres, los homosexuales, los jóvenes, los indígenas y los negros, entre otros, constituyen manifestaciones de resistencia de sujetos individuales y colectivos que buscan la creación de mundos de la vida alternativos. Al respecto, afirma Tubert (1996): “Así, Nancy Hartsock (1987) se pregunta por qué, justo cuando en la historia de Occidente las poblaciones previamente silenciadas comenzaron a hablar por sí mismas, se torna sospechoso el concepto de sujeto y la posibilidad de descubrir (o crear) una verdad liberadora." (p. 307) En este sentido, tanto el psicoanálisis como el feminismo ofrecen un bagaje discursivo que permite adentrarse en esta búsqueda de espacios subjetivos y sociales nuevos, en los que las relaciones de poder endurecidas se disuelvan gradualmente. Sin embargo, la posición deconstruccionista del posmodernismo se presenta, a la vez, como una alternativa frente a las tendencias esencialistas y ahistóricas que a menudo dificultan la autoreflexión crítica dentro del psicoanálisis y el feminismo.

En un intento por deconstruir las mistificadas y complejas relaciones entre sexualidad, agresión y autonomía en la mujer, quisiera abordar, a continuación, algunas condiciones psicosociales particulares, que influyen en la constitución de la identidad en la mujer.

\section{Sexualidad, agresión y autonomía: separación y reconocimiento en el desarrollo de la mujer como sujeto}

El desarrollo de la identidad en la mujer está atravesado por la paradoja que la igualdad de género entre la hija y la madre contiene, es decir, la discrepancia entre la dependencia y la autonomía frente a un mismo objeto. La niña pequeña va a estar desde el principio confrontada con la tensión inevitable entre identificación y desidentificación, o dicho de otra forma, entre el vincularse y el separarse de un objeto igual a sí misma. Por un lado, la niña experimenta la necesidad urgente de separarse de la madre, de convertirse en otra, en un individuo separado, por otro lado, debe identificarse con ella, con sus atributos femeninos y maternos. De acuerdo con King (1995), esta situación paradójica en la relación madre-hija abre un doble potencial: por una parte, una fuente de conflictos difíciles de manejar, por otra parte, la posibilidad de identificarse con la potencia sexual y creativa de la madre. Esta semejanza personificada en la igualdad de género entre la madre y la hija puede ser considerada, siguiendo a Chodorow (1978), como una relación que estimula la capacidad de vínculos, caracterizados por la cercanía, la confianza y la lealtad. La relación íntima entre la madre y la hija puede estimular tanto la empatía, la compasión y la preocupación hacia el otro, como fortalecer en la niña la capacidad de manifestar de forma abierta sus sentimientos. Por otra parte, la semejanza corporal y psíquica, que impregna la relación madrehija, puede ser vista como un componente que estimula la autonomía y la individuación. La fuerte ambivalencia que caracteriza la relación madre-hija va estar marcada por la rivalidad, la envidia y el odio, que inevitablemente acompaña el procreso de separación y el conflicto edípico en la mujer. Las experiencias de decepción e impotencia que pertenecen a la relación madre-hija fortalecen en la niña la agresión de separación, que posibilita la curiosidad, el deseo de saber y la tendencia a buscar un mundo que se encuentra más allá de la relación diádica con la madre.

Ya muy temprano aparece el padre como un tercero con un rol significativo en el proceso de separación-individuación, representando al mundo externo en la temprana relación madre-hijo (Abelin, 1971, 1980; Rotmann, 1978; Benjamin, 1988; Rohde-Dachser, 1990, 1991). También el padre desempeña un rol específico como mediador en la tensión entre lo extraño y lo propio en el desarrollo de la identidad (Bosse, 1992). Así pues, el padre viene a introducir en la relación madrehija, lo diferente, lo desconocido. Éste representa aquello vivido como extranjero, que a menudo es asociado con el establecimiento de roles sociales y un sistema de valores colectivo. En este sentido, se podría afirmar, que la confrontación entre lo femenino y lo masculino se encuentra en la base del proceso de separación e individuación que hace posible el desarrollo de la identidad de género. Tanto en la temprana triangulación de los primeros años, como en el proceso de separación durante la adolescencia, la ambivalencia entre los impulsos agresivos y sexuales, entre el deseo de vincularse 
y, a la vez, separarse de las figuras de identificación, va a jugar un papel central en el desarrollo de un proyecto de vida autónomo.

La agresión de separación y la necesidad de una desidentificación de los padres en la adolescencia, aparecen de esta forma, determinadas en gran parte por la posibilidad de identificarse, y a la vez, distanciarse, tanto de los componentes femenino-maternos internalizados, como de los masculino-paternos. En este sentido, aparece la tensión entre los género como condición fundamental para el desarrollo de la sexualidad femenina y para la comprensión de la formación de la identidad femenina (Reiche, 1990 y King, 1995). La tensión entre los géneros representa, en el nivel psíquico, el enfrentamiento entre el polo femenino y el masculino en la propia identidad de género. A partir de esta tensión aparece el conflicto entre los componentes pasivos y activos, que pertenecen tanto a la masculinidad como a la feminidad en cada individuo. Esta tensión es, al mismo tiempo, producto de la relación real entre los hombres y las mujeres. Esta relación posibilita, mediante el enfrentamiento crítico entre los géneros, tanto el reconocimiento de la diferencia, como de la mutua dependencia entre los géneros. El proceso de individuación del sí mismo constituye una tensión permanente entre la capacidad de separación, y al mismo tiempo, de identificación con respecto a los padres, la familia y las tradiciones culturales. La capacidad de identificación y desidentificación con respecto a las imágenes maternas y paternas, en términos de un reconocimiento de la diferencia entre los géneros, sin caer en la exclusión o expulsión del otro, constituye un requisito fundamental para la creación de experiencias nuevas. En el caso de la mujer se podría hablar de la posibilidad de creación de su propia feminidad, es decir, del proceso de constitución de una identidad femenina autónoma.

Durante la adolescencia, las manifestaciones intensas de la agresión que tiende a la separación constituyen experiencias fundamentales en el proceso de desidentificación de los padres (Bosse, 1995). Cuando esta agresión de separación no se expresa de una forma adecuada se puede producir tanto una ruptura de las relaciones con la familia y una negación de la dependencia hacia los padres, como manifestaciones destructivas o autodestructivas de la agresión. Bajo estas condiciones, el proceso de desidentificación se va a dificultar como consecuencia de la devaluación y la idealización de los diversos componentes de las figuras paternas. Condiciones que obstaculizan la transición de una adolescencia creativa hacia el desarrollo de la autonomía y la autoconsciencia en la etapa adulta. Cómo se da este paso entre la infancia, la adolescencia y la etapa adulta en las mujeres y hasta qué punto la lucha por un proyecto de vida propio se ve culturalmente estimulado u obstasculizado, constituye un interrogante fundamental para la comprensión de la identidad femenina.

En este sentido, se podría afirmar que la integración de los polos femenino y masculino en el desarrollo psicosexual de la identidad en la mujer no ocurre a menudo. Por el contrario tiende a producirse un proceso de identificación, en el que un polo va a ser reprimido por el otro. Este proceso desemboca en dos modelos de identificación estereotipados. Por un lado, existe la posibilidad de una fuerte identificación de la niña hacia el padre y de una idealización de la imago paterna, acompañada de una represión de la sexualidad femenina y de las experiencias placenteras asociadas con la imago materna. La devaluación de la feminidad surge como consecuencia de una desidentificación de los componentes amenazantes y persecutorios de la madre preedípica. Por otro lado, existe la posibilidad de una identificación con una imago materna desexualizada, lo cual implica una intensificación de las fases preedípicas y de nuevo una idealización de la imago paterna. Ésta no va a estar acompañada de una identificación con el padre, sino de una dependencia intensa hacia el hombre. En ambos casos, la desidealización de la imago paterna, como parte del trabajo de separación en la resolución del Complejo de Edipo y del proceso de desprendimiento durante la adolescencia, aparece inhibida. En estas dos posibilidades nos encontramos con una escisión en la formación de la identidad femenina. Ya sea que, a través de una identificación fálica, la mujer deba devaluar su propia feminidad, o que mediante una identificación preedípica con la madre, deba permanecer encerrada en una feminidad excluyente. En este sentido, Kristeva (1974) se refiere, como opciones excluyentes, a dos arquetipos femeninos del cristianismo, la mujer extática y la mujer meláncolica. En ambos modelos de identificación la posibilidad de incorporar componentes masculinos y femeninos va a ser imposible porque la diferencia entre los géneros no va a ser reconocida. En este sentido, sería valioso explorar de que forma la tensión entre los componentes femeninos y masculinos, el conflicto entre lo tradicional y lo moderno, y la ambivalencia entre la dependencia y la autonomía, están presentes en las imágenes sobre la feminidad y la maternidad predominantes actualmente. 
"Las mujeres aman demasiado" dice el título de un bestseller norteamericano sobre la dependencia de las mujeres en el amor (Norwood, 1985). El arte, la literatura, los medios de comunicación, y con ellos, la teoría psicoanalítica, no se cansan de hablarnos del amor apasionado y a menudo incomprensible de las mujeres, del amor como un lugar donde el sí mismo autónomo del sujeto femenino se disuelve en un mar de fusiones, agravios y desengaños. La supuesta tendencia de la mujer a una dependencia extrema hacia el hombre, su urgente necesidad de reconocimiento en el amor y la disolución de la feminidad en la maternidad, aparecen como imágenes mistificadas en las que lo femenino queda atrapado en una imposibilidad o mayor dificultad de la mujer para acceder a un proyecto de vida autónomo. Pareciera como si en el amor y en la maternidad se escenificara, de forma privilegiada para la mujer, el conflicto extremo entre su posición social tradicional y su anhelo de transgredirla. En este sentido, algunos de los temas fundamentales en relación con la diferencia entre los géneros, que en los últimos años dentro de la teoría psicoanalítica se han venido discutiendo, están directamente relacionados con el vínculo entre la sexualidad y la agresión femeninas y el desarrollo de un proyecto de vida autónomo en la mujer. El análisis de las relaciones entre el amor, la agresión y lo extranjero en la mujer permite acercarse a la forma en que estos componentes conflictivos se encuentran entrelazados con la tendencia hacia la autonomía, la autoafirmación y la autorealización.

El problema de la autonomía en el sujeto se constituye como un enfrentamiento autoreflexivo con las espectativas sociales y las tradiciones culturales, es decir, no sólo como adaptación frente a los controles sociales e institucionales, sino también como resistencia. La autonomía aparece como actitud autoconsciente del individuo sobre sí mismo y sobre los otros. Tanto la agresión que posibilita la autonomía y la capacidad de autoafirmarse, como la manifestación activa del deseo sexual, son componentes necesarios para el desarrollo de un proyecto de vida propio.

Al respecto, se vuelve fundamental explorar de que forma el enfrentamiento de un sujeto femenino consigo mismo y con la sociedad tiende a implicar, todavía hoy en día, un proceso autodestructivo que se puede manifestar en aquellas tendencias depresivas o masoquistas que se asocian típicamente con la mujer. En todo caso, la posición de autodenigración típica de una estructura psíquica depresivo-masoquista, con fuertes sentimientos de culpa y una intensa necesidad de castigo, asociados a menudo dentro del psicoanálisis, con una imagen pasiva, desexualizada y poco agresiva de la mujer, no parecen representar la compleja realidad de la mujer en la actualidad.

Sin embargo, aunque la mujer pueda ser agresiva en forma abierta y activa, al hacerlo, su agresión se vuelve ilegítima, manifestación de fuerzas extrañas vividas como provenientes de un mundo extranjero que amenaza con arrasar el orden social. Los componentes de la agresión que tienden a la autonomía y la autoafirmación en la mujer, aquellas actitudes que buscan la diferencia y la distancia frente al otro, se transforman de esta manera, tanto en la mirada de los otros como en la de sí misma, en agresión violenta y autodestructiva.

La comprensión de la agresión femenina en comparación con las formas de manifestación de la agresión masculina conforma una esquina vital en los estudios de género con orientación psicoanalítica. De nuevo nos encontramos con una imagen mistificada escindida de la mujer. Por un lado, la mujer aparece como menos agresiva y belicosa que el hombre. Se le considera con tendencias depresivo-masoquistas, que coinciden, más bien, con una imagen desexualizada, pasiva y sin poder de la mujer -y en particular de la madre- y con una representación desvitalizada de lo femenino. Por otro lado, la figura de la mujer agresiva, que seduce y destruye a los hombres, es transformada, dentro del psicoanálisis, en la madre omnipotente, castrante y devoradora. Estas imágenes deformadas sobre la mujer nos llevan a la urgencia de repensar tanto el mito de la madre desexualizada, sin poderes creadores y eróticos, como el mito de la madre arcaica, englobante, sin frustración, ni separación (Kristeva 1991, p. 445). En estas imágenes mistificadas de la madre se encuentran condensados aquellos componentes de la sexualidad y la agresión femeninas que han sido socialmente tabuisados y que generalmente solo a través de fantasías masculinas, que están al servicio de la producción inconsciente, encuentran una forma de manifestarse.

Este doble rostro de lo materno evoca la íntima relación entre la feminidad y la muerte que ha dominado en la cultura occidental desde la antigüedad; vínculo en el que lo femenino sintetizado en la imagen de la Gran Madre Tierra se transforma en una metáfora de la muerte (Macho, 1987, cit. por Rohde-Dachser, 1991). Siguiendo a Bronfen (1987), podríamos decir que lo mismo ocurre con la metáfora del cadáver bello en la literatura occidental de los últimos dos siglos. La madre representa el lugar del origen, aquel sitio insondable de dónde todos provenimos, el útero materno, el cuerpo fertilizado, y finalmente, la tierra fecunda. Al mismo tiempo, simboliza el lugar del retorno, del 
deseo irrenunciable a fusionarnos de nuevo con los orígenes, con la tierra madre en el regazo de la muerte. De acuerdo con Kristeva (1980), esta relación con la madre está teñida por una intensa ambivalencia, que transforma el cuerpo materno en representante de lo abyecto, en el lugar donde el deseo irrevocable se fusiona con un miedo más allá del lenguaje, un horror impronunciable hacia el "cuerpo intocable, imposible, ausente de la madre" (p. 14). De acuerdo con Rohde-Dachser (1991), la imagen de la madre mala, en la teoría psicoanalítica y más allá de ésta, fue convertida en el chivo expiatorio de la modernidad, en aquella otra mujer, que surge como producto de una demonización de lo femenino. Lo femenino-materno aparece, entonces, como representante de aquellas imágenes asesinas, que como las Erinias, la Esfinge o la Medusa, todas ellas mujeres, han sido convertidas en figuras monstruosas que horrorizan y que hay que destruir para protegerse de la destrucción y la muerte que representan. Las imágenes psíquicas sobre la feminidad, las fantasías originarias sobre los órganos genitales femeninos, sobre el lugar de nuestra madre en la escena primaria, sobre el embarazo y el parto, sobre los regalos que cargamos en el cuerpo -los niños, las heces y los penesquedan enlazadas con esta imagen primitiva de la madre mala que ha sido mistificada dentro del psicoanálisis. Son estas imágenes mistificadas de la sexualidad y la agresión femeninas las que deben ser deconstruidas mediante el estudio sistemático sobre las experiencias diversas que conforman lo femenino.

Hoy en día nos encontramos, tanto en la literatura, el arte, la ciencia y los medios de comunicación, como también en la teoría psicoanalítica con imágenes sobre la feminidad mistificadas, en las que las mujeres son asociadas con una carencia en la capacidad de actuar autonómamente y de imponer su voluntad. Al respecto afirma Musfeld (1997): "Yo sigo en mis discusiones la hipótesis, de que no sólo en la identidad femenina, sino también en las concepciones feministas sobre la mujer, el significado de la agresión sigue siendo ignorado y permanece excluido tanto de la discusión, como de las experiencias subjetivas y las imágenes sobre sí mismo" (p. 8). Al mismo tiempo, para las mujeres se han abierto, tanto en el mundo privado como en el mundo público, nuevos espacios potenciales en los que la tendencia hacia la autonomía y la autoafirmación no sólo es estimulada sino que también aparece como legítima. Las características asociadas tradicionalmente con la feminidad como la capacidad para el vínculo y la compasión frente a los otros, en cierta medida, no son vistos necesariamente como irreconciliables con la capacidad y los deseos hacia la diferencia, la separación y la autodeterminación. La maternidad y la vida familiar empiezan, lentamente, en la cotidianidad, a coexistir con los espacios de trabajo de la mujer en el mundo público, para dejar de presentarse como espacios sociales totalmente irreconciliables o contradictorios. Son estos espacios potenciales los que podrían hacer posible una experiencia alternativa tanto de la agresión y la sexualidad femeninas como de la capacidad de la mujer para la autorealización y la autoreflexión.

En este sentido se vuelve fundamental explorar como las mujeres, actualmente, se resisten a la adaptación patriarcal que la sociedad les sigue exigiendo, cómo escogen caminos propios y de qué formas intentan mantener o recuperar su dignidad, orgullo y autovaloración como sujetos. Se vuelve imperante estudiar de qué manera las manifestaciones de la agresión que estimulan la autonomía y la capacidad de acción autónoma, así como, las manifestaciones activas de la sexualidad femenina están presentes en las imágenes dominantes sobre lo femenino. En otras palabras, explorar cómo las condiciones de socialización y de constitución de la identidad femenina posibilitan o dificultan el desarrollo de un proyecto de vida autónomo en las mujeres. La luchas por recuperar la autoconfianza y la autovaloración, así como las manifestaciones conscientes de la agresión y la sexualidad como condiciones fundamentales para el desarrollo de la autonomía en las mujeres deben ser abordadas a partir de las transformaciones que se vienen desarrollando en las relaciones de poder entre los géneros.

\section{Referencias}

Bauman, Z. (1992/1995). Ansichten der Postmoderne. Hamburg: Argument.

Benjamin, J. (1988). The bonds of love. Psychoanalysis, feminism, and the problem of domination. New York: Pantheon Books.

Benjamin, J. (1995/1997). Sujetos iguales, objetos de amor. Ensayos sobre el reconocimiento y la diferencia sexual. Buenos Aires: Paidós. 
Bernstein, D. 1993). Weibliche genitale Ängste und die typischen Formen ihrer Bewältigung. Psyche 47, 6, 530-560.

Berrón, L. (comp.) (1997). Las mujeres y el poder. San José: Editorial Mujeres.

Bosse, H. (1995) Nicht länger Daddys Liebling. Schicksale schöpferischer Weiblichkeit in der Adoleszenz. En Heinemann, E. y Krauss, G. (Eds.) Geschlecht und Kultur. Beiträge zur Ethnopsychoanalyse 3. (pp.61-100). Nürnberg: ISKA.

Braun, C. (1985/1994). Nicht Icb: Logik, Lüge, Libido. Frankfurt am Main: Neue Kritik.

Bronfen, E. (1987). Die schöne Leiche. Weiblicher Tod als motivische Konstante von der Mitte des 18. Jahrhunderts bis in die Moderne. En Berger, R. y Stephan, I. (Eds.) Weiblichkeit und Tod in der Literatur. Köln: Böhlau.

Burin, M.; Dio Bleichmar, E. (compiladoras). (1996). Género, psicoanálisis, subjetividad. Buenos Aires: Paidós.

Burin, M.; Meler, I. (1998). Género y familia. Poder, amor y sexualidad en la construcción de la subjetividad. Buenos Aires: Paidós.

Chasseguet-Smirgel, J. (1976). Freud and the female sexuality. The consideration of some blind spots in the exploration of the "Dark Continent". En Int. J. Psycho-Anal 57: 275-286.

Chasseguet-Smirgel, J. (1986/1988). Zwei Bäume im Garten. Zur psychischen Bedeutung der Vaterund Mutterbilder. München/Wien: Internationale Psychoanalyse.

Chodorow, N. (1978/1994). Das Erbe der Mütter. Psychoanalyse und Soziologie der Gescblecbter. München: Frauenoffensive.

Clément, C. (1975/1988). The guilty one. En Cixous, H. y Clément, C. The newly born woman (pp. 1-59). Minneapolis: University of Minnesota Press.

Cixous, H. (1975/1988). Sorties: Out and Out: Attacks/Ways Out/ Forays. En Cixous, H. y Clément, C. The newly born woman (pp. 61-132). Minneapolis: University of Minnesota Press.

Coria, C. (1986/1991). El sexo oculto del dinero. Buenos Aires: Paidós.

Coria, C. (1993). Los laberintos del éxito. Ilusiones, pasiones y fantasmas femeninos. Barcelona: Paidós.

Dio Bleichmar, E. (1985/1989). El feminismo espontáneo de la histeria. Estudio de los trastornos narcisistas de la feminidad. México, D.F.: Fontamara.

Dio Bleichmar, E. (1997/1998). La sexualidad femenina. De la niña a la mujer. Barcelona: Paidós.

Erdheim, M. (1982/1992). Die gesellschaftliche Produktion von Unbewußtheit. Eine Einfübrung in den ethnopsychoanalytischen Prozeß. Frankfurt am Main: Suhrkamp. Narcea.

Everingham, C. (1997). Maternidad: autonomia y dependencia. Un estudio desde la psicología. Madrid:

Fernández, A.M. (compiladora). (1992). Las mujeres en la imaginación colectiva. Una bistoria de discriminación y resistencias. Buenos Aires: Paidós.

Fernández, A.M. (1993). La mujer de la ilusión. Pactos y contratos entre hombres y mijeres. Buenos Aires: Paidós.

Flax, J. (1990/1995). Psicoanálisis y feminismo. Pensamientos fragmentarios. Madrid: Cátedra.

Freud, S. (1905a/1901). Bruchstück einer Hysterie-Analyse. Gesammelte Werke, Bd. 5, Frankfurt am Main, Fischer, 1966, 161-286.

Freud, S. (1905b). Drei Abhandlungen zur Sexualtheorie. GW, Bd. 5, 29-145.

Freud, S. (1915). Triebe und Triebschicksale. GW, Bd. 10, 210-232.

Freud, S. (1916/17). Vorlesungen zur Einführung in die Psychoanalyse. GW, Bd. 11.

Freud, S. (1924). Das ökonomische Problem des Masochismus. GW, Bd.13, 369-383. 17-30.

Freud, S. (1925). Über einige psychische Folgen des anatomischen Geschlecbtsunterschieds. GW, Bd. 14,

Freud, S. (1931) Über die weibliche Sexualität. GW, Bd. 14, 515-537.

Freud, S. (1933). Neue Folgen der Vorlesungen zur Einfübrung in die Psychoanalyse. GW, Bd. 15.

Giverti, E. y Fernández, A.M. (1989/1992). La mujer y la violencia invisible. Buenos Aires: Sudamericana.

Hagemann-White, C. (1978). Die Kontroverse um die Psychoanalyse in der Frauenbewegung. Psyche 51, 8: 732-763. 5, 21-36.

Hidalgo, R. (1992). La feminidad, la subjetividad y el poder en América Latina. En Reflexiones

Hidalgo, R. y Chacón, L. (2001). Cuando la feminidad se trastoca en el espejo de la maternidad. Conversaciones con mujeres penalizadas por cometer infanticidio. Un análisis psicosocial. San José: Editorial de la Universidad de Costa Rica. 
Hidalgo, R. (2002). Die Medea des Euripides. Zur Psychoanalyse weiblicher Aggression und Autonomie. Giessen, Psychosozial Verlag (en prensa).

Hirsch, M. (1989). The mother/danghter plot. Narrative, psychoanalysis, feminism. Bloomington/Indianapolis: Indiana University Press.

Irigaray, L. (1977/1987). The sex which is not one. New York: Cornell University Press.

Irigaray, L. (1998). Ser dos. Buenos Aires: Paidós.

Kestenberg, J. (1968). Outside and inside. male and female. Journal of the American Psychoanal. Association 16: 457-520.

Kestenberg, J. (1988). Der komplexe Charakter weiblicher Identität. Betrachtungen zum Entwicklungsverlauf. Psyche 42, 4: 349-365.

King, V. (1995). Die Urszene der Psychoanalyse. Adoleszenz und Geschlechterspannung im Fall Dora. Stuttgart: Internationale Psychoanalyse.

Kristeva, J. (1974/1986). About cbinese women. New York: Marion Boyars Publishers. Press.

Kristeva, J. (1980/1982). Powers of horror. An essay on abjection. New York: Columbia University

Kristeva, J. (1991/1992). Women's time. En Warhol, R. y Price Herndl, D. Feminism and anthology of literary theory and criticism (pp.31-48). New York: Rutgers State University.

Lagarde, M. (1990). Madreesposas, prisioneras, locas, monjas y putas. México D.F.: Universidad Autónoma de México.

Langer, M. (1951/1983). Matermidad y sexo. Buenos Aires: Paidós.

Lorenzer, A. (1986/1988). Tiefenhermeneutische Kulturanalyse. En: A. Lorenzer (Eds.). Kultur-Analysen (pp. 11-98).Frankfurt am Main: Fischer.

Masters, W.H. y Johnson, V.E. (1966). Human sexual response. Boston: Little Brown.

Mitscherlich-Nielsen, M. (1975). Psychoanalyse und weibliche Sexualität. Psyche 29, 769-788.

Mitscherlich-Nielsen, M. (1978). Zur Psychoanalyse der Weiblichkeit. Psyche 32, 8: 669-694.

Mitscherlich-Nielsen, M. (1985). Die friedfertige Frau. Frankfurt am Main: Fischer.

Moi, T. (1988). Teoría literaria feminista. Madrid: Cátedra.

Musfeld, T. (1996/1997). Im Schatten der Weiblichkeit. Über die Fesselung weiblicher Kraft und Potenz. durch das Tabu der Aggression. Berlin: Reihe Perspektiven.

Nadig, M. (1990). Die gespaltene Frau. Mutterschaft und öffentliche Kultur. Psyche 44, 53-70.

Norwood, R. (1985/1988). Wenn Frauen zu sehr lieben. Die heimliche Sucht gebraucht zu werden. Hamburg: Rowohlt.

Poluda-Korte, E. S. (1992). Freud und die Töchter. Versuch einer Emanzipation von patriarchalen Vorurteilen in der Psychoanalyse. Jahrbuch der Psychoanalyse 29, 92-139.

Reiche, R. (1990). Geschlechterspannung. Eine psychoanalytische Untersucbung. Frankfurt am Main: Fischer.

Rohde-Dachser, C. (1990). Über töchterliche Existenz. Offene Fragen zum weiblichen Ödipuskomplex. Psychosomatische Medizin und Psychoanalyse 36, 303-315.

Rohde-Dachser, C. (1991/1992). Expedition in den dunklen Kontinent. Weiblichkeit im Diskurs der Psychoanalyse. Berlin/Heidelberg: Springer.

Rohde-Dachser, C. (1996). Aggression in weiblichen und männlichen Lebensentwürfen. En:

Bell, K. y Höhfeld, K. (Eds.) Aggression und seelische Krankheit (pp. 75-90). Gießen: Psychosozial.

Schlesier, R. (1981/1990). Mythos und Weiblichkeit bei Sigmund Freud: Zum Problem von Entmythologisierung und Remythologisierung in der psychoanalytischen Theorie. Frankfurt am Main: Hain.

Stemann-Achempong, S. (1996). Der phantastische Unterschied. Zur psychoanalytischen Theorie der Geschlechtsidentität. Göttingen: Vandenhoeck und Ruprecht.

Stoller, R. (1968). Sex and gender. Vol. I. New York: Jason Aronson.

Stoller, R. (1975). Sex and gender. Vol. II. New York: Jason Aronson.

Theweleit, K. (1977/2000). Männerphantasien 1/2. Frankfurt am Main: Stroemfeld.

Tubert, S. (1991). Mujeres sin sombra. Maternidad y tecnología. Madrid: Siglo XXI.

Tubert, S. (1995). Introducción a la edición española. En: Flax, J. (1990/1995). Psicoanálisis y feminismo. Pensamientos fragmentarios (pp. 7-41). Madrid: Cátedra.

Tubert, S. (1996). Psicoanálisis, feminismo, posmodernismo. En: Burin, M. y Dio Bleichmar, E. (compiladoras). (1996). Género, psicoanálisis, subjetividad (pp. 289-313). Buenos Aires: Paidós. 